Article

\title{
The Effect of Direct Democratic Participation on Citizens' Political Attitudes in Switzerland: The Difference between Availability and Use
}

\author{
Anna Kern \\ Centre for Citizenship and Democracy, University of Leuven, 3000 Leuven, Belgium; E-Mail: anna.kern@kuleuven.be
}

Submitted: 8 November 2016 | Accepted: 25 January 2017 | Published: 27 March 2017

\begin{abstract}
According to advocates of direct democracy, it is important to involve citizens more directly in political decision-making processes in order to create a democratic linkage between citizens and the political system. Indeed, some studies have demonstrated that citizens who live in direct democracies have higher levels of trust in political institutions and a higher sense of political efficacy. However, not all empirical evidence confirms this relationship. In a recent article on Switzerland, it was shown that, while the availability of direct democratic rights enhances trust in political institutions, using those rights actually initiates distrust. In this paper I expand the analysis of Bauer and Fatke (2014) and test whether the different effects of availability of direct democratic rights and the frequency of their use also hold for broader measures of trust in political institutions and political efficacy. I find that, even though an increased use of direct democratic measures is associated with lower levels of confidence in authorities on the cantonal level, this relationship is no longer apparent when applying a more comprehensive measurement of trust in political institutions.
\end{abstract}

\section{Keywords}

direct democracy; external efficacy; political attitudes; political participation; political trust

\section{Issue}

This article is part of a multidisciplinary issue of Politics and Governance, edited by Andrej J. Zwitter (University of Groningen, The Netherlands) and Amelia Hadfield (Canterbury Christ Church University, UK).

(C) 2017 by the author; licensee Cogitatio (Lisbon, Portugal). This article is licensed under a Creative Commons Attribution 4.0 International License (CC BY).

\section{Introduction}

A legitimate, stable and well-functioning polity is based on a strong relation between citizens and the state. However, in most established democracies the mechanisms that connect citizens with the political system have experienced fundamental changes in the last few decades (Dalton \& Welzel, 2014). Given this development, proponents of direct democracy argue that one way of sustaining and strengthening the linkage between citizens and the state is to involve citizens more directly in the political decision-making process. The theory of participatory democracy provides a theoretical foundation for this argument. Political philosophers adhering to this theory assume that participation has an educative and an integrative function that connects citizens with the community (Barber, 1984; Pateman, 1970). In recent years, the attitudinal effect of direct democratic participation has attracted renewed interest in the literature. Most of this research was conducted in countries that provide citizens with extensive mechanisms to engage directly in decision-making, notably the United States and Switzerland. Yet, the findings of those studies seem rather inconclusive and-even more striking - the results of some analyses are in sharp contrast with what participatory democrats would predict.

In one of these studies on the relationship between direct democracy and trust in cantonal authorities in Switzerland, Bauer and Fatke (2014) found that while levels of trust are higher in cantons offering extensive direct democratic rights, they are lower in cantons where citizens made frequent use of these rights. It was concluded that a more frequent use of direct democratic rights results in stronger feelings of distrust. Dyck (2009) obtained similar results in the American context, as he shows that ballot initiatives in the United States decrease trust in state governments. These studies suggest that, while the availability of direct democratic procedures 
might have the effect that is envisioned in the literature, the fact that citizens actually use those opportunities might be an indication of distrust rather than trust. As a result, they conclude that the use of direct democratic procedures might initiate political distrust.

However, when looking closely at the indicators used to measure political trust in these two studies, it is clear that Bauer and Fatke (2014) as well as Dyck (2009) relied on a rather narrow measurement only capturing trust in authorities on the canton or the state level. While this negative relationship between such specific measures of trust and the use of direct democratic procedures could be conceivable, it remains to be investigated whether we also find the same effect when using a more encompassing measure of trust in political institutions. A broader operationalization of trust in political institutions seems essential because it can represent "a comprehensive assessment of the political culture that is prevailing in a political system" (Hooghe, 2011, p. 270). In line with David Easton $(1965,1975)$, I consider trust in political institutions as an expression of support for the political system and not just the result of satisfaction with performance (Chanley, Rudolph, \& Rahn, 2000; Marien \& Hooghe, 2011; Miller \& Listhaug, 1990). Consequently, trust in political institutions represents a form of legitimacy (Hetherington, 1998; Zmerli \& Hooghe, 2011). From a normative point of view, a negative effect of direct democracy on trust in political institutions would be alarming as it would endanger the functioning and the stability of the democratic system. I therefore rely on trust in political institutions in its broad definition and furthermore expand the analysis by including a second measure directly related to the classical conceptualization of a democratic civic culture, namely: external political efficacy, or in other words: the belief that governmental institutions and public officials are responsive to the interests, needs and demands of citizens. Political efficacy is evidently a very distinct concept from political trust, but the entire research tradition on the civic culture stresses that it is crucial for citizens to see themselves as active participants in the political process. Both concepts therefore represent important political attitudes linking citizens and the state. Already in Almond and Verba's The Civic Culture (1963) both attitudes were considered to be an essential element of a democratic civic culture.

To investigate the relationship between having and using direct democratic rights and support for the political system, I rely on the models of Bauer and Fatke (2014) and extend their analysis. I do so by including other, more comprehensive attitudinal measurements than in the original study, namely trust in political institutions and external political efficacy. It is assumed that these attitudes are developed during childhood and that they are relatively independent of outputs in the short run and hence comparatively stable over time (Easton, 1975; lyengar, 1980). To measure trust in political institutions and external political efficacy, I draw on two different datasets from Switzerland: the Swiss Electoral Stud- ies "Selects" and the Swiss Household Panel (SHP). The Selects survey 2007 is a post-election survey based on a national representative sample and the SHP is a rich, representative, household-based study aimed to observe social change in Switzerland since 1999. I start with a replication of the results of Bauer and Fatke (2014) with the use of datasets from 2007. As is well-known, Switzerland has a unique history of a rather frequent use of direct democracy, and therefore the country can serve as an ideal test case.

\section{Political Participation and "Thick" Democracy}

In her seminal work Participation and Democratic Theory, Pateman (1970) describes participatory democracy which underlines the educative value of political participation as opposed to liberal democracy which mainly highlights the instrumental value of political participation for the participants. Pateman summarizes three functions of political participation. First, political participation has an educative function, second, it has an integrative function and third, it facilitates the acceptance of decisions. For participatory democrats, the first and most important function is the educative function of political participation. Citizens who participate in political decision-making are assumed to learn to take other interests than their own into account when engaging in participatory processes. Moreover, they are expected to learn that public and private interests are linked and they are stimulated to deliberate with each other. It is through participation that individuals are expected to acquire the qualities needed for the political system to work. Consequently, it is through "participation in common seeing and common work" that members of a "strong" democratic community are transformed into citizens (Barber, 1984, p. 232). While Rousseau described the educative effects of political participation in the context of the citystate, John Stuart Mill described these in the scope of a modern political system, thus extending Rousseau's description of the educative function of participation. As Pateman (1970) points out, according to Mill, the local level of government plays a crucial role in "educating" the individual. In order to participate effectively in government, citizens need to develop the necessary qualities at the local level. Mill writes "a political act, to be done only once in a few years, and for which nothing in the daily habits of the citizen has prepared him, leaves his intellect and his moral dispositions very much as it found them" (Mill, as cited in Pateman, 1970, p. 30). Following this theory, citizens need a context in which they can practice their engagement in the decision-making process. While the local level of politics seems like a suitable context for Mill, Cole and Pateman stress the importance of participatory structures in the workplace or even in all "lower level authority structures" (Pateman, 1970, p. 35) as environments where citizens can experience and practice participating in decision-making procedures. According to this theory, we can expect, that individuals 
who frequently engage in decision-making procedures, develop more positive, democratic characteristics, such as community-mindedness, political efficacy and satisfaction with political institutions and authorities, and are generally more supportive of the democratic system (Barber, 1984; Finkel, 1987; Pateman, 1970). What remains unclear, however, is whether this theory helps us to understand the potential consequences of direct democratic decision-making. Can participation in direct democratic procedures fulfil the same role as participation at the local level or in the workplace is expected to do?

Bowler and Donovan (2002) discuss this question explicitly. They argue that, although direct democratic procedures may not have the same educative value as participation in the workplace, compared to the election of representatives, direct democratic procedures should have a greater effect on political efficacy. This reasoning is built on the argument that, in comparison to the standard electoral context of representative democracy, citizens in democracies with direct democratic procedures must decide more often on collective issues and public policies. Through direct democratic decision-making citizens get an "occasional voice in government" and feel that the government is listening to them "or has to listen to them at some point" (Bowler \& Donovan, 2002, p. 376). But citizens might not only feel that government listens to them, they might also feel that they are trusted, which is a crucial point according to Frey (1997, p. 1046), as their self-esteem is enhanced and their intrinsic motivation is "crowded in". Finally, when comparing citizens in representative democracies with citizens in systems with direct democratic procedures, the latter might experience more positive political attitudes and democratic orientations, because they are more satisfied with the democratic procedures (Hibbing \& Theiss-Morse, 2001; Persson, Esaiasson, \& Gilljam, 2013; Smith \& Tolbert, 2004). In accordance with these arguments, it can be assumed that the central claim of participatory democracy applies to systems with extensive direct democratic procedures and that citizens who live in these systems are characterized by more positive attitudes towards the political system.

Indeed, some studies find evidence for the "educative benefit" of direct democratic decision-making. These analyses suggest that citizens who live in direct democracies are characterized by higher levels of external efficacy, i.e. they believe more strongly that the government is responsive to their demands (Bowler \& Donovan, 2002; Hero \& Tolbert, 2004; Mendelsohn \& Cutler, 2000; Smith \& Tolbert, 2004), their levels of political knowledge and interest are higher (Mendelsohn \& Cutler, 2000; Smith, 2002) and they are more engaged in civic groups and associations (Smith \& Tolbert, 2004; Tolbert, McNeal, \& Smith, 2003).

However, not all empirical evidence confirms this direct positive relationship between direct democratic procedures and political attitudes and behavior. Whereas Gilens, Glaser and Mendelberg (2001) cannot find a di- rect effect of propositions on political attitudes, they show that it is the salience of the propositions that seems to affect citizens' perception of having a say in political issues. The absence of a direct effect between direct democratic procedures and both internal and external efficacy is also ascertained by Schlozman and Yohai (2008) and by Dyck and Lascher (2009) who show that the effect of direct democracy on internal political efficacy depends on citizens' political knowledge.

A striking contrast between studies that find a positive effect of direct democracy on political attitudes and those that find no effect, is that scholars who find no effect distinguished between the institutional availability of direct democratic rights and the frequency of their actual use. This important distinction is not always clearly made in the literature and might explain the mixed evidence. It thus remains an open question whether citizens become more trusting and efficacious by actually making use of direct democratic procedures or whether it is sufficient that these opportunities are available to them, regardless of whether they actually use these additional possibilities to voice their opinion.

\section{The Availability and Use of Direct Democratic Procedures}

Several studies show that there is a difference between the effect of the availability of direct democratic procedures on political attitudes and the effect of actually using those procedures. Dyck (2009) finds that the availability of direct democratic initiatives in the United States does not affect trust in the state government, but that their actual use affects trust negatively. This negative effect is confirmed in the study on trust in cantonal authorities in Switzerland (Bauer \& Fatke, 2014), where the authors also find a positive effect on trust when direct democratic procedures are available. Therefore, the question arises whether we should expect the availability and the use of direct democratic procedures to have different effects on political attitudes.

From the perspective of the theory of participatory democracy the results of Bauer and Fatke (2014) and Dyck (2009) are highly relevant as they seem to run counter to expectations. For adherents of this theory, using direct democratic procedures should lead to positive effects, as it is the act of participation itself that is expected to build and nurture democratic orientations and political attitudes. In order to obtain this psychological effect, the classical writers advocate full participation. However, Pateman (1970, p. 73) remarks that in this context a modification of the theory is required, because empirical evidence shows that "even the mere feeling that participation is possible, even situations of pseudoparticipation have beneficial effects on confidence, job satisfaction, etc.". One might thus argue that citizens might be more supportive if they have the feeling that they are able to participate, independent of whether they actually do or not. The argument that government is 
responsive and considers citizens as trustworthy should be valid for citizens independent of their actual engagement. Moreover, citizens might be more satisfied with the decision-making process in a system where direct democratic procedures are available, regardless of whether they participate or not. In conclusion, the theory of participatory democracy does not seem to provide a theoretical foundation to explain the different effects on political attitudes between the availability and the use of direct democratic procedures. The first hypothesis thus reads as follows:

H1. Citizens who live in systems that provide extensive direct democratic decision-making processes are characterized by higher levels of trust in political institutions and higher external political efficacy.

Consequently, it remains questionable how we can then explain the negative relation between the use of direct democratic rights and trust in canton and state level authorities, found by Bauer and Fatke (2014) and Dyck (2009). The authors give a number of reasons why this negative relationship was to be expected. If we start from the premise of liberal democracy instead of participatory democracy, and assume that participation mainly serves to protect citizens' individual interests, direct democracy can be used as a sanctioning instrument. In agreement with this assumption citizens, in states or cantons frequently employing this instrument, might get the impression that sanctioning is a necessity and that elected representatives are not to be trusted (Bauer \& Fatke, 2014). This would be in line with the argument made by Rosanvallon (2008) that critical citizens should exert a rather strict oversight on the behaviour of political decisionmaking elites. Dyck (2009) argues that being constantly questioned and pressured to give their opinion, initiatives might undermine the authority of elected officials, which might again lead to increasing distrust among the population. At the same time, Bauer and Fatke (2014, p. 54) point out that representatives who are constantly controlled "might no longer feel the same obligation to honour the trust of being voted into office", which might encourage them to "follow their own agenda" or to tweak contested legislation in the phase of implementation where citizens have less influence. Such behaviour might by implication enhance citizens' distrust and diminish their sense of political efficacy. While this reasoning suggests that direct democratic participation affects citizen's attitudes towards the political system, the argument that direct democratic processes are used as a sanctioning mechanism rests on the reverse causal mechanism, namely that participating citizens are already dissatisfied with the performance of political institutions. Using an instrumental variable regression, Bauer and Fatke (2014) find evidence for the former causal mechanism that participation affects trust. MacKenzie and Warren (2012) however, argue that participation might stem from a lack of trust. Following this reasoning, citizens might choose to use their direct democratic rights after evaluating how trustworthy their cantonal or state authorities are and how responsive they are to their interest. This reasoning would be in line with Gamson (1968, pp. 46-47) who stated that "high trust in authorities implies some lack of necessity for influencing them". Consequently, one would expect that citizens will only use direct democracy if there is a necessity to influence policy-makers.

While both mechanisms seem plausible for explaining a negative relationship between trust in cantonal or state authorities - the dependent variables in the studies of Bauer and Fatke (2014) and Dyck (2009) - and engagement in direct democratic decision-making procedures, it remains unclear whether these explanations can also be applied to a broader notion of trust in political institutions and to external political efficacy. The argument that frequent use of direct democratic procedures reduces political trust, as those procedures are used as sanctioning mechanisms seems to hold mainly in cases where citizens are dissatisfied with the output and the performance of political authorities and institutions. The reasoning seems to hold mainly for trust in specific institutions and authorities and is therefore expected to depend mainly on the perceived output and performance of those institutions. In fact, the dependent variables in the above mentioned studies are, as Dyck $(2009$, p. 550) points out himself, "strongly tied to incumbent evaluations".

However, regarding the broader measurement of trust in political institutions, the reasoning seems less straightforward. Trust in political institutions is an assessment of general political structures and procedures, and it tends to be more durable and independent of institutions' performances and output in the short run. Only after a continuous experience of discontent over a long period of time, general feelings of trust in political institutions might gradually erode (Easton, 1975; Hooghe, 2011). Therefore, I argue that while there are good reasons to assume that using direct democratic procedures is related to evaluations of democratic output and performance of specific political institutions, it is far less clear why using direct democratic procedures should lead to an erosion of trust in political institutions more generally.

Also regarding external political efficacy, a negative relationship due to the use of direct democratic rights can hardly be expected based on the theory. In fact, Hero and Tolbert (2004) argue that, in states with frequent exposure to direct democracy, citizens should be more inclined to perceive government as more responsive. A negative effect on external efficacy would rather be expected as a result of non-participation (Finkel, 1987). I therefore argue that the negative effect of using direct democratic procedures found in the study of trust in cantonal and state authorities does not hold in a study of trust in political institutions and external political efficacy. This leads us to the second hypothesis: 
H2. The negative effect of using direct democratic procedures does not hold if we study trust in political institutions and external political efficacy.

I test those hypotheses using Swiss population data, but before presenting the results, I will introduce the datasets, measures and method.

\section{Data, Measures and Method}

First of all the results of Bauer and Fatke (2014) are replicated. In a second step, their models are extended to the study of trust in political institutions and political efficacy. For this purpose, I will use the same data as they did, namely the $\mathbf{2 0 0 7}$ dataset from the Swiss Electoral Studies "Selects" that contains not only trust in cantonal authorities but also other items allowing us to create a comprehensive measure of trust in political institutions. As the Selects dataset does not contain any measure of political efficacy, I use a different dataset for the analysis of political efficacy, namely the 2007 wave of the SHP. Both datasets are based on random probability samples from the Swiss population and for both studies data were collected in a similar period of time. This allows us to include the same variables of interest, i.e. the availability and use of direct democratic instruments and to keep the analysis as comparable as possible to the original analysis of Bauer and Fatke (2014). However, as the SHP only contains one question on the perception of system responsiveness, the analysis has to be restricted to external political efficacy.

\subsection{Dependent Variables}

In comparison to the study of Bauer and Fatke (2014), I expand the analysis to support for the system as a whole and therefore I want to capture the level of trust in political institutions more broadly. As Easton explains (1975, p. 444) diffuse support "refers to evaluations of what an object is or represents-to the general meaning it has for a person-not of what it does". Therefore, if we start from Easton's concept of diffuse support, we need indicators for support that are independent of outputs and performances in the short run. Marien (2011) argues that the question about how much people trust their country's parliament, government, political parties, legal system, the police, etc. does tap into a more encompassing form of political trust-although we cannot rule out that respondents think about how these institutions are functioning. According to Hooghe (2011, p. 270), the latent concept that is built on these items "can be conceptualized as a comprehensive evaluation of the political culture that is prevailing within a political system....". Hence, instead of focusing on for example satisfaction with the functioning of an institution or authority, I decided to measure trust in political institutions based on the following items included in the Selects 2007 survey: trust in the federal council, trust in parliament, trust in national political parties, trust in local authorities, trust in justice/courts, trust in the police and trust in cantonal authorities (the item that was used in the first step of the analysis). Assuming that this latent concept of trust in political institutions reflects the trustworthiness of the political system as a whole, it is expected that the different items on trust in actors and institutions load on one single latent variable. For each item respondents indicated their level of trust on an 11-point scale ( 0 = "no trust"; $10=$ "full trust"). Based on these items, I conducted a factor analysis and found, in line with previous research, that these items load one single factor (Marien, 2011; Zmerli, Newton, \& Montero, 2007) with an Eigenvalue of 3.214 and 46 per cent explained variance (Table 1 ). This measurement of trust in political institutions is thus onedimensional and coherent. This finding confirms the argumentation of Hooghe (2011) that citizens do not distinguish between the functioning of various political institutions, and therefore this factor was used as measure of trust in political institutions.

Table 1. Factor analysis of trust in political institutions. Source: (Selects, 2007).

\begin{tabular}{ll}
\hline Item & Factor loading \\
\hline Trust in the federal council & 0.720 \\
Trust in parliament & 0.744 \\
Trust in national political parties & 0.644 \\
Trust in local authorities & 0.624 \\
Trust in cantonal authorities & 0.749 \\
Trust in justice/courts & 0.646 \\
Trust in the police & 0.600 \\
\hline \% explained variance & 0.459 \\
Eigenvalue & 3.214
\end{tabular}

Notes: Estimates are factor loadings from a principal factor analysis.

For the measurement of external political efficacy I relied on the question "How much influence do you think someone like you can have on government policy?" in the SHP 2007 personal questionnaire, respondents could answer on an 11-point scale with 0 indicating "no influence" and 10 indicating "a very strong influence". Following Niemi, Craig and Mattei (1991) this item primarily taps respondents' beliefs about the responsiveness of governmental authorities and institutions to citizen demands, i.e. their sense of external political efficacy.

\subsection{Independent Variables}

As I aim to build on the analysis of Bauer and Fatke (2014) I use the same measures as they did for the independent variables of interest, namely the availability of direct democratic rights and the use of those rights. For the availability of those rights, I thus rely on the same index that was created by Fischer (2009). This index represents a summary index of four sub-indices capturing 
the strength of four direct democratic institutions in 2003: the initiatives for constitutional and statutory changes, the fiscal referendum on expenditure projects and the referendum for laws. Each sub-index ranges from one to six and reflects the evaluation of the requirements for those four institutions, more specifically the signature requirements needed for optional referendums and the fiscal thresholds for fiscal referendums. Therefore, each sub-index measures the availability and the imposed hurdles for each of the four direct democratic procedures in the Swiss cantons.

Regarding the actual use of these direct democratic instruments, I use the average number of cantonal initiatives and optional referendums per year between 2002 and 2006 generated by Bauer and Fatke (2014) based on data from the year book Année Politique Suisse, which is generally considered as a comprehensive account of political events in Switzerland.

\subsection{Control Variables}

I furthermore control for variables that could affect trust in political institutions and political efficacy on the individual as well as on the cantonal level. Again, since I am interested in an analysis that is as close as possible to the one presented by Bauer and Fatke (2014), I also include exactly the same control variables. For the analysis of trust in political institutions this is: gender, age, the level of education, and the perception of the economic development. Also, I include a dummy variable for Catholic denomination and unemployment status. Thanks to their detailed documentation of data sources, I could also include the same canton-level control variables, namely the financial state of cantons in 2006 and the primary national income per capita in 2005.

For the analysis of external political efficacy, I include the same control variables, expect for religious denomination and the perception of economic development. I excluded religious denomination, because in the literature I found no reason to assume that religious denomination should affect the sense of external efficacy. Economic evaluations, on the other hand, are expected to affect general political attitudes (Bowler \& Donovan, 2002). However, the item used in the Selects survey is not included in the SHP, so instead I included a variable that measures the respondent's evaluation of his or her standard of living in the past year. Respondents could answer on a scale from 0 ("greatly worsened") to 10 ("greatly improved").

In both the analysis of trust in political institutions and the analysis of external political efficacy, I dropped the canton Nidwalden, because the Selects survey 2007 does not contain data for this canton. This resulted in 3,858 respondents for the analysis of trust in political institutions and 4,094 respondents for the analysis of external political efficacy. In both analyses these respondents are nested in cantons, which is why I rely on varying intercept models.

\section{Results}

In the first step, I replicate the analysis of trust in cantonal authorities of Bauer and Fatke (2014) (their Table 2). Not surprisingly, since using the same data, I find virtually the same results (see Annex, Table A). As the final model, which contains all the control variables and both variables of interest shows, the availability of direct democratic rights positively affects trust in cantonal authorities while their actual use has a significant, negative effect. So this first step clearly confirms the conclusion of Bauer and Fatke.

In the second step, I replicate the exact same analysis but this time I replace the dependent variable with the variable that captures trust in political institutions (Table 2). The first remarkable observation is that there is considerably less variance in trust in political institutions on the second level compared to the variance in trust in cantonal authorities. Our replication of the interceptonly model of trust in cantonal authorities reveals that about 6 per cent of the entire variance is found on the second level. For the intercept-only model of trust in political institutions, this is only 2.3 per cent. This confirms the assumption that trust in cantonal authorities captures evaluations of the performance of specific institutions apparently which vary quite substantially across the 25 cantons. The broader attitude of trust in political institutions, on the other hand, captures an attitude that varies primarily between individuals independent of where they live. Therefore, when attempting to explain the variance in trust in political institutions, we have to focus mainly on individual characteristics. This observation already challenges the first hypothesis claiming that citizens living in cantons that provide more extensive direct democratic decision-making processes are characterized by higher levels of trust in political institutions and external efficacy. The effects of those individual-level variables, however, are similar compared to the effects in the analysis of trust in cantonal authorities. While sex does not seem to matter, trust in political institutions seems to rise with age and the level of education. Ceteris paribus, Catholics seem to have higher levels of trust in political institutions, whereas unemployment is associated with lower levels of trust in political institutions. Also, citizens who believe that the state of the economy has worsened are significantly less trustful. Looking at the second-level control variables shows that a canton's financial state and national income do not affect individuals' level of trust in political institutions.

Finally, I turn to our variables of interest. The first model reveals that the availability of direct democratic rights does affect levels of trust in political institutions positively, which seems in line with what the theory of participatory democracy would predict. Similarly to the analysis of trust in cantonal authorities, but in sharp contrast to what we expected, we find that in the second model, the use of democratic instruments has a significant, negative effect on trust in political institutions. 
Table 2. Random-intercept models of direct democracy and trust in political institutions. Source: Selects (2007).

\begin{tabular}{|c|c|c|c|c|c|c|}
\hline \multirow[b]{3}{*}{ Age } & \multicolumn{6}{|c|}{ Trust in political institutions } \\
\hline & \multicolumn{2}{|c|}{1} & \multicolumn{2}{|c|}{ II } & \multicolumn{2}{|c|}{ III } \\
\hline & $0.002 * *$ & $(0.001)$ & $0.002 * *$ & $(0.001)$ & $0.002 * *$ & $(0.001)$ \\
\hline Sex & 0.036 & $(0.030)$ & 0.036 & $(0.030)$ & 0.036 & $(0.030)$ \\
\hline Education & $0.022 * * *$ & $(0.004)$ & $0.023 * * *$ & $(0.004)$ & $0.022 * * *$ & $(0.004)$ \\
\hline Catholic (Dummy) & $0.122 * * *$ & $(0.032)$ & $0.123 * * *$ & $(0.032)$ & $0.121^{* * *}$ & $(0.032)$ \\
\hline Economy worse (Dummy) & $-0.281 * * *$ & $(0.052)$ & $-0.284 * * *$ & $(0.052)$ & $-0.281 * * *$ & $(0.052)$ \\
\hline Unemployed (Dummy) & $-0.233^{*}$ & $(0.126)$ & $-0.235^{*}$ & $(0.126)$ & $-0.233^{*}$ & $(0.126)$ \\
\hline $\begin{array}{l}\text { Availability of direct } \\
\text { democratic rights }\end{array}$ & $0.051^{* *}$ & $(0.026)$ & & & 0.036 & $(0.031)$ \\
\hline $\begin{array}{l}\text { Actual use of direct } \\
\text { democratic instruments }\end{array}$ & & & $-0.047^{*}$ & $(0.025)$ & -0.027 & $(0.031)$ \\
\hline Financial state & -0.001 & $(0.026)$ & -0.000 & $(0.026)$ & -0.002 & $(0.026)$ \\
\hline National income & 0.144 & $(0.516)$ & 0.818 & $(0.555)$ & 0.463 & $(0.627)$ \\
\hline Constant & $-0.568^{* *}$ & $(0.228)$ & $-0.595 * *$ & $(0.232)$ & $-0.604 * * *$ & $(0.228)$ \\
\hline Observations & \multicolumn{2}{|c|}{3,858} & \multicolumn{2}{|c|}{3,858} & \multicolumn{2}{|c|}{3,858} \\
\hline Number of groups & \multicolumn{2}{|c|}{25} & \multicolumn{2}{|c|}{25} & \multicolumn{2}{|c|}{25} \\
\hline$-2 *$ loglikelihood & \multicolumn{2}{|c|}{10,165} & \multicolumn{2}{|c|}{10,166} & \multicolumn{2}{|c|}{10,164} \\
\hline ICC in \% & \multicolumn{2}{|c|}{0.016} & \multicolumn{2}{|c|}{0.016} & \multicolumn{2}{|c|}{0.015} \\
\hline
\end{tabular}

Notes: The dependent variable is trust in political institutions. Standard errors in parentheses. Sign..*** $p<0.01,{ }^{* *} p<0.05, * p<0.1$.

Yet, both effects disappear when we include them together in one model (Model III) and at this point, the conclusions differ strongly from the conclusions resulting from the analysis of trust in cantonal authorities. Neither the availability nor the use of direct democratic procedures seems to affect trust in political institutions. On the one hand, this result contradicts the first hypothesis. On the other hand, the negative effect of using direct democratic instruments disappears and this supports the second hypothesis. So, while using direct democratic measures apparently cannot enhance trust in political institutions, the good news for advocates of participatory democracy is that at least it does not seem to reduce it either.

In a final step we turn to the analysis of external political efficacy (Table 3 ). This variable varies even less across cantons than trust in political institutions. Only about 2 per cent of the variance in the intercept-only model is detected at the second level. Concerning the individual level variables, we find different effects than for trust in political institutions. We find that while older people seem to have more trust in political institutions than younger citizens, the sense of external political efficacy seems to diminish with age. Moreover, citizens with a higher level of education appear to have more trust in political institutions and also more external political efficacy, the latter being also the case for citizens who feel that their standard of living has improved.

Turning to the variables of interest, we find that the availability of direct democratic rights has a positive effect on external efficacy (Model I) and this effect also holds when we include the use of direct democratic instruments into the same model (Model III). Using direct democratic instruments, however, does not affect external efficacy, neither in the second nor in the final model
(Model III). Apparently, citizens have a stronger feeling that government is responsive to their demands and interests in cantons where direct democratic instruments are extensively available and hurdles to use them are low. And this effect remains observable independent of how often those instruments are actually used.

\section{Discussion and Conclusion}

Summarizing the results, we can state that there is only limited evidence for the first hypothesis which claimed that the availability and the use of direct democratic procedures has a positive effect on political attitudes that tap support for the political system. While we could not find any effect for the analysis of trust in political institutions, levels of external efficacy are significantly higher in cantons which are characterized by an extensive availability of direct democratic procedures. However, it has to be remarked that there is generally a lot less variance of both trust in political institutions as well as in external political efficacy across the 25 cantons compared to the variance that is found for trust in cantonal authorities. So while evaluations of cantonal authorities depend to a substantial degree on the canton where respondents live, levels of general trust in political institutions and feelings of external efficacy are hardly dependent on this administrative division. I interpret this finding as evidence for the claim that trust in authorities captures evaluations of performances of specific institutions rather than trust in political institutions as such.

Concerning the second hypothesis, we did find evidence to support the claim that while there are good reasons to argue that using direct democratic instruments affects trust in cantonal authorities negatively, such a 
Table 3. Random-intercept models of direct democracy and external political efficacy. Source: SHP.

\begin{tabular}{|c|c|c|c|c|c|c|}
\hline \multirow[b]{3}{*}{ Age } & \multicolumn{6}{|c|}{ External Political Efficacy } \\
\hline & \multicolumn{2}{|c|}{1} & \multicolumn{2}{|c|}{ II } & \multicolumn{2}{|c|}{ III } \\
\hline & $-0.015^{* * *}$ & $(0.003)$ & $-0.015^{* * *}$ & $(0.003)$ & $-0.015^{* * *}$ & $(0.003)$ \\
\hline Sex & -0.053 & $(0.086)$ & -0.052 & $(0.086)$ & -0.053 & $(0.086)$ \\
\hline Education & $0.095^{* * *}$ & $(0.015)$ & $0.094 * * *$ & $(0.015)$ & $0.095^{* * *}$ & $(0.015)$ \\
\hline Living standard improved & $0.158 * * *$ & $(0.035)$ & $0.158 * * *$ & $(0.035)$ & $0.157 * * *$ & $(0.035)$ \\
\hline Unemployed (Dummy) & 0.434 & $(0.370)$ & 0.437 & $(0.370)$ & 0.436 & $(0.370)$ \\
\hline $\begin{array}{l}\text { Availability of direct } \\
\text { democratic rights }\end{array}$ & $0.192 * * *$ & $(0.054)$ & & & $0.181^{* * *}$ & $(0.061)$ \\
\hline $\begin{array}{l}\text { Actual use of direct } \\
\text { democratic instruments }\end{array}$ & & & -0.113 & $(0.070)$ & -0.025 & $(0.068)$ \\
\hline Financial state & 0.079 & $(0.065)$ & 0.085 & $(0.076)$ & 0.074 & $(0.065)$ \\
\hline National income & 0.974 & $(1.187)$ & $3.323^{* *}$ & $(1.506)$ & 1.358 & $(1.523)$ \\
\hline Constant & $1.724 * * *$ & $(0.592)$ & $1.572 * *$ & $(0.690)$ & $1.666 * * *$ & $(0.606)$ \\
\hline Observations & \multicolumn{2}{|c|}{4,094} & & & \multicolumn{2}{|c|}{4,094} \\
\hline Number of groups & \multicolumn{2}{|c|}{25} & & & \multicolumn{2}{|c|}{25} \\
\hline$-2 *$ loglikelihood & \multicolumn{2}{|c|}{19,331} & & & \multicolumn{2}{|c|}{19,339} \\
\hline ICC in \% & \multicolumn{2}{|c|}{0.004} & & & \multicolumn{2}{|c|}{0.009} \\
\hline
\end{tabular}

Notes: The dependent variable is external political efficacy. Standard errors in parentheses. Sign.:*** $p<0.01,{ }^{* *} p<0.05,{ }^{*} p<0.1$.

negative effect is unexpected in the more general study of trust in political institutions. In fact, using direct democratic instruments seems to affect neither trust in political institutions nor external political efficacy. If direct democratic instruments are used as sanctioning mechanism for negatively perceived performances and outputs of authorities, this can explain the negative effect on evaluations of cantonal authorities and institutions. However, there is little reason to assume that broader attitudes of support for the system are also affected.

I believe that this study can contribute to a better understanding of the mixed evidence that was found in previous studies concerning the link between direct democratic procedures and political attitudes. In this regard, two aspects should be considered. First, in some studies a difference is made between availability of direct democratic rights and the use of direct democratic instruments and because results differ quite substantively this study confirms the importance of this distinction. Second, different measures of trust in political institutions have been employed in those studies and different theories have been applied to explain the results. This study underlines the importance of clearly distinguishing between these different measures. Participatory democracy can primarily serve to understand the long-term effects of extensive participation in different areas of life on support for the political system. Liberal democracy, on the other hand, which stresses the protective function of participation, might help to explain evaluations of political outputs and performances of specific authorities and institutions.

But what do these results tell us about the applicability of the theory of participatory democracy to direct democratic procedures? The findings of Bauer and Fatke (2014) and Dyck (2009) seem inexplicable from the perspective of participatory democracy, as they suggest that using more opportunities for direct participation "initiates distrust", which our analysis can qualify to some degree. While an increase in the use of direct democratic measures might diminish trust in authorities on the state or canton level, it does not affect the general feeling of support for the political system. So in the end it is not too bad of a result for adherents of this theory. However, these results can be interpreted in two ways.

On the one hand, the results show that providing citizens with more direct democratic instruments appears to affect their trust in cantonal authorities positively as well as their sense of external efficacy-and this independent of how much those instruments are used. Apparently, having the option of interfering is already sufficient to strengthen citizens' trust in cantonal authorities and their perceived government responsiveness. A possible reason could be that citizens are satisfied with the democratic process itself, regardless of whether they use it or not. This interpretation would be in line with the claim of Dalton and Welzel (2014) that new generations of "assertive citizens" are characterized by a strong appreciation of inputoriented notions of democracy. Hence, if direct participation can lead to more critical citizens, who are supportive of the system in general, some scholars might argue that this represents a desirable situation from a democratic perspective (Dalton \& Welzel, 2014; Rosanvallon, 2008).

On the other hand, support for the first hypothesis that links direct democratic participation with political support remains limited, which might call the general applicability of the theory of participatory democ- 
racy for direct democratic systems into question. As we have seen for both trust in political institutions as well as for political efficacy, by far most of the variance is found on the individual level and can therefore not be explained by the variance in the extent of direct democratic decision-making. One argument could be that, compared to other countries, Swiss cantons all provide relatively extensive opportunities of participation in decision-making processes and that the variance within Switzerland is therefore too limited. Another, even more fundamental reason could be that participatory democrats seem to envision an entirely different society with multiple participation possibilities in the workplace, during leisure activities and at all levels of the political system. Moreover, as Schlozman and Yohai $(2008$, p. 472) point out, these theorists stress the importance of deliberation and the benefits of deliberation cannot arise in plebiscites "where voters do not deliberate or where their interests clash". So scholars should be careful when applying the theory of participatory democracy to direct democratic systems and not blindly base their assumptions on a theory that envisions an entire reconfiguration of todays' political, economic and societal institutions.

\section{Acknowledgements}

I thank Sofie Marien, Marc Hooghe, Ann-Kristin Kölln, Damien Bol and the participants of the panel "Institutional Effects on Political Attitudes and Values" at the ECPR General Conference 2015 as well as the two anonymous reviewers for thoughtful comments on earlier ideas and drafts of this paper. The research leading to these results has received funding from the European Research Council under the European Union's Seventh Framework Programme (FP7/2007-2013) / ERC grant agreement $n^{\circ} 295920$.

\section{Conflict of Interests}

The author declares no conflict of interests.

\section{References}

Almond, G., \& Verba, S. (1963). The civic culture. Political attitudes and democracy in five nations. Princeton, NJ: Princeton University Press.

Barber, B. R. (1984). Strong democracy: Participatory politics for a new age. Berkeley, CA: University of California Press.

Bauer, P. C., \& Fatke, M. (2014). Direct democracy and political trust: Enhancing trust, initiating distrust-Or both? Swiss Political Science Review, 20(1), 49-69.

Bowler, S., \& Donovan, T. (2002). Democracy, institutions and attitudes about citizen influence on government. British Journal of Political Science, 32(2), 371-390.

Chanley, V. A., Rudolph, T. J., \& Rahn, W. M. (2000). The origins and consequences of public trust in government. A time series analysis. Public Opinion Quar- terly, 64, 239-256.

Dalton, R. J., \& Welzel, C. (Eds.). (2014). The civic culture transformed: From allegiant to assertive citizens. Cambridge: Cambridge University Press.

Dyck, J. J. (2009). Initiated distrust: Direct democracy and trust in government. American Politics Research, 37(4), 539-568.

Dyck, J. J., \& Lascher Jr., E. L. (2009). Direct democracy and political efficacy reconsidered. Political Behavior, 31(3), 401-427.

Easton, D. (1965). A systems analysis of political life. Englewood Cliffs, NJ: Prentice Hall.

Easton, D. (1975). A re-assessment of the concept of political support. British Journal of Political Science, 5(4), 435-457.

Finkel, S. E. (1987). The effects of participation on political efficacy and political support: Evidence from a West German panel. Journal of Politics, 49(2), 441-464.

Fischer, J. (2009). Development of direct democracy in Swiss cantons between 1997 and 2003 (Paper No. 16140). Munich: Munich Personal RePEc Archive. Retrieved from https://mpra.ub.uni-muenchen.de/ 16140

Frey, B. S. (1997). A constitution for knaves crowds out civic virtues. The Economic Journal, 107(443), 1043-1053.

Gamson, W. (1968). Power and discontent. Homewood, IL: Dorsey Press.

Gilens, M., Glaser, J., \& Mendelberg, T. (2001). Having a say: Political efficacy and direct democracy. Paper Presented at the Annual Meeting of the American Political Science Association, San Francisco, USA.

Hero, R. E., \& Tolbert, C. J. (2004). Minority voices and citizen attitudes about government responsiveness in the American states: Do social and institutional context matter? British Journal of Political Science, 34(1), 109-121.

Hetherington, M. J. (1998). The political relevance of political trust. The American Political Science Review, 92(4), 791-808.

Hibbing, J. R., \& Theiss-Morse, E. (2001). Process preferences and American politics: What the People want government to be. The American Political Science Review, 95(1), 145-153.

Hooghe, M. (2011). Why there is basically only one form of political trust. British Journal of Politics and International Relations, 13(2), 269-275.

Iyengar, S. (1980). Subjective political efficacy as a measure of diffuse support. The Public Opinion Quarterly, 44(2), 249-256.

Kaase, M., \& Newton, K. (1995). Beliefs in government. Oxford: Oxford University Press.

MacKenzie, M. K., \& Warren, M. E. (2012). Two trustbased uses of mini-publics in democratic systems. In J. Parkinson \& J. Mansbridge (Eds.), Deliberative systems: Deliberative democracy at the large scale (pp. 95-124). Cambridge: Cambridge University Press. 
Marien, S. (2011). Measuring political trust across time and space. In M. Hooghe \& S. Zmerli (Eds.), Political trust. Why context matters (pp. 13-46). Colchester: ECPR Press.

Marien, S., \& Hooghe, M. (2011). Does political trust matter? An empirical investigation into the relation between political trust and support for law compliance. European Journal of Political Research, 50(2), 267-291.

Mendelsohn, M., \& Cutler, F. (2000). The effect of referendums on democratic citizens: Information, politicization, efficacy and tolerance. British Journal of Political Science, 30(4), 669-698.

Miller, A. \& Listhaug, O. (1990). Political parties and confidence in government. A comparison of Norway, Sweden and the United States. British Journal of Political Science, 20(3), 357-386.

Niemi, R. G., Craig, S. C., \& Mattei, F. (1991). Measuring internal political efficacy in the 1988 National Election Study. The American Political Science Review, 85(4), 1407-1413.

Pateman, C. (1970). Participation and democratic theory. Cambridge: Cambridge University Press.

Persson, M., Esaiasson, P., \& Gilljam, M. (2013). The effects of direct voting and deliberation on legitimacy beliefs: An experimental study of small group decision-making.
European Political Science Review, 5(3), 381-399.

Rosanvallon, P. (2008). Counter-democracy: Politics in an age of distrust. Cambridge: Cambridge University Press.

Schlozman, D., \& Yohai, I. (2008). How initiatives don't always make citizens: Ballot initiatives in the American states, 1978-2004. Political Behavior, 30(4), 469-489.

Smith, D. A., \& Tolbert, C. J. (2004). Educated by initiative: The effects of direct democracy on citizens and political organizations in the American. Ann Arbor, MI: University of Michigan Press.

Smith, M. A. (2002). Ballot initiatives and the democratic citizen. Journal of Politics, 64(3), 892-903.

Tolbert, C. J., McNeal, R. S., \& Smith, D. A. (2003). Enhancing civic engagement: The effect of direct democracy on political participation and knowledge. State Politics \& Policy Quarterly, 3(1), 23-41.

Zmerli, S., \& Hooghe, M. (Eds.). (2011). Political trust: Why context matters. Colchester: ECPR Press.

Zmerli, S., Newton, K., \& Montero, J. R. (2007). Trust in people, confidence in political institutions, and satisfaction with democracy. In J. W. van Deth, J. R. Montero, \& A. Westholm (Eds.), Citizenship and involvement in European democracies: A comparative analysis (pp. 35-65). London: Routledge.

\section{About the Author}

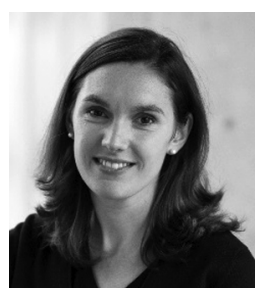

Anna Kern is a postdoctoral researcher at the Centre for Citizenship and Democracy of the University of Leuven. She has written a PhD dissertation on the topic of political participation. Her main research interests are in political participation, political equality and political attitudes. Previously, her work has been published in, among others, Comparative European Politics, Party Politics, West European Politics and Social Science Research. 
Annex

Table A. Random-intercept models of direct democracy and external trust in cantonal authorities.

\begin{tabular}{|c|c|c|c|c|c|c|}
\hline & \multicolumn{6}{|c|}{ Trust in cantonal authorities } \\
\hline & 1 & II & III & IV & V & VI \\
\hline Age & $\begin{array}{l}0.007^{* * *} \\
(0.002)\end{array}$ & $\begin{array}{l}0.007^{* * *} \\
(0.002)\end{array}$ & $\begin{array}{l}0.007^{* * *} \\
(0.002)\end{array}$ & $\begin{array}{l}0.007^{* * *} \\
(0.002)\end{array}$ & $\begin{array}{l}0.007^{* * *} \\
(0.002)\end{array}$ & $\begin{array}{l}0.007^{* * *} \\
(0.002)\end{array}$ \\
\hline Sex & $\begin{array}{c}0.053 \\
(0.061)\end{array}$ & $\begin{array}{c}0.055 \\
(0.061)\end{array}$ & $\begin{array}{c}0.053 \\
(0.061)\end{array}$ & $\begin{array}{c}0.055 \\
(0.061)\end{array}$ & $\begin{array}{c}0.053 \\
(0.061)\end{array}$ & $\begin{array}{c}0.054 \\
(0.061)\end{array}$ \\
\hline Education & $\begin{array}{l}0.027^{* * *} \\
(0.009)\end{array}$ & $\begin{array}{l}0.028^{* * *} \\
(0.009)\end{array}$ & $\begin{array}{l}0.028^{* * *} \\
(0.009)\end{array}$ & $\begin{array}{l}0.028 * * * \\
(0.009)\end{array}$ & $\begin{array}{l}0.028^{* * *} \\
(0.009)\end{array}$ & $\begin{array}{l}0.028^{* * *} \\
(0.009)\end{array}$ \\
\hline Catholic (Dummy) & $\begin{array}{l}0.196 * * * \\
(0.067)\end{array}$ & $\begin{array}{l}0.197 * * * \\
(0.066)\end{array}$ & $\begin{array}{l}0.188^{* * *} \\
(0.067)\end{array}$ & $\begin{array}{l}0.200 * * * \\
(0.067)\end{array}$ & $\begin{array}{l}0.199 * * * \\
(0.067)\end{array}$ & $\begin{array}{l}0.198^{* * *} \\
(0.067)\end{array}$ \\
\hline Economy worse (Dummy) & $\begin{array}{l}-0.456^{* * *} \\
(0.103)\end{array}$ & $\begin{array}{l}-0.445^{* * *} \\
(0.103)\end{array}$ & $\begin{array}{l}-0.457^{* * *} \\
(0.103)\end{array}$ & $\begin{array}{l}-0.444^{* * *} \\
(0.103)\end{array}$ & $\begin{array}{l}-0.452 * * * \\
(0.103)\end{array}$ & $\begin{array}{l}-0.445^{* * *} \\
(0.103)\end{array}$ \\
\hline Unemployed (Dummy) & $\begin{array}{l}-0.350 \\
(0.263)\end{array}$ & $\begin{array}{c}-0.344 \\
(0.263)\end{array}$ & $\begin{array}{l}-0.349 \\
(0.263)\end{array}$ & $\begin{array}{c}-0.344 \\
(0.263)\end{array}$ & $\begin{array}{l}-0.350 \\
(0.263)\end{array}$ & $\begin{array}{l}-0.345 \\
(0.263)\end{array}$ \\
\hline $\begin{array}{l}\text { Availability of direct } \\
\text { democratic rights }\end{array}$ & & $\begin{array}{l}0.282^{* * *} \\
(0.067)\end{array}$ & & $\begin{array}{l}0.275^{* * *} \\
(0.070)\end{array}$ & & $\begin{array}{l}0.198^{* *} \\
(0.080)\end{array}$ \\
\hline $\begin{array}{l}\text { Actual use of direct } \\
\text { democratic instruments }\end{array}$ & & & $\begin{array}{l}-0.151^{* *} \\
(0.075)\end{array}$ & & $\begin{array}{l}-0.243^{* * *} \\
(0.073)\end{array}$ & $\begin{array}{c}-0.134 * \\
(0.079)\end{array}$ \\
\hline Financial state & & & & $\begin{array}{c}0.015 \\
(0.072)\end{array}$ & $\begin{array}{c}0.021 \\
(0.076)\end{array}$ & $\begin{array}{c}0.012 \\
(0.068)\end{array}$ \\
\hline National income & & & & $\begin{array}{c}0.356 \\
(1.383)\end{array}$ & $\begin{array}{l}3.914^{* *} \\
(1.567)\end{array}$ & $\begin{array}{c}1.966 \\
(1.618)\end{array}$ \\
\hline Constant & $\begin{array}{l}6.013^{* * *} \\
(0.187)\end{array}$ & $\begin{array}{l}4.846^{* * *} \\
(0.329)\end{array}$ & $\begin{array}{l}6.221^{* * *} \\
(0.210)\end{array}$ & $\begin{array}{l}4.644 * * * \\
(0.605)\end{array}$ & $\begin{array}{l}4.519 * * * \\
(0.649)\end{array}$ & $\begin{array}{l}4.451^{* * *} \\
(0.587)\end{array}$ \\
\hline Observations & 4,225 & 4,225 & 4,225 & 4,225 & 4,225 & 4,225 \\
\hline Number of groups & 25 & 25 & 25 & 25 & 25 & 25 \\
\hline$-2 *$ loglikelihood & 17,646 & 17,634 & 17,642 & 17,633 & 17,636 & 17,630 \\
\hline ICC in \% & 0.055 & 0.030 & 0.046 & 0.029 & 0.033 & 0.026 \\
\hline
\end{tabular}

